\title{
Gender Differences in the Effects of Internet Access on Work Absenteeism in the US
}

\author{
Wesley A. Austin, Ph.D. \\ Department of Economics and Finance \\ University of Louisiana at Lafayette \\ P.O. Box 44570 \\ Lafayette, Louisiana 70504-4570, USA \\ Michael W. Totaro, Ph.D. \\ College of Informatics \\ University of Louisiana at Lafayette \\ P.O. Box 43930 \\ Lafayette, Louisiana 70504-3930, USA
}

\begin{abstract}
Considerable debate has ensued over the effects technologies such as the Internet might have on society and culture. In the economics literature, the effect of technologies on the labor market has been the subject of substantial research. In this analysis, a large sample of respondents is stratified into males and females and gender differences in two related questions are addressed: First, does Internet access, and presumably use, affect absenteeism from work differently for males and females? Second, to what extent does the degree of Internet access affect male vs. female work absenteeism? Regression results indicate that greater Internet access increases workplace absenteeism and gender differences are present.
\end{abstract}

Keywords: labor productivity, Internet use, absenteeism, gender

\section{Introduction}

Within about the past ten years, Internet use has increased significantly. In fact, according to Pew Internet \& American Life Project Surveys, the percentage of U. S. online users has increased from about $46 \%$ in 2000 to approximately 87\% in January 2014 (Pew Internet \& American Life Project Surveys, 2015). Presumably, such an increase in Internet use could also suggest a concomitant decrease in time spent on non-Internet activities; such activities might include spending time with one's family and friends, attending social or athletic events, traveling, and so-called "quiet" time such as reading and other reflective activities. By extension, one may inquire whether there might also be an increase in work absenteeism, as a direct or indirect result of mounting Internet activity. If so, then what level of Internet use ultimately results in one's missing work? Or, stated differently, if distinctions could be made among light or heavy Internet access and use, then which of these, if any, result in possible work absenteeism? Moreover, if work absenteeism is impacted by Internet access, what gender differences, if any, might exist?

Why is the potential impact of Internet access and use on work absenteeism relevant for economics? Absenteeism can have connecting effects to labor productivity, wages, work hours, etc. This analysis augments the literature by investigating effects on work absenteeism, i.e. days missed due to "skipping" and illness or injury, which has not been widely studied despite potential effects on numerous labor market variables. Also, gender differences are described, which may aid researchers in understanding topics such as male/female attitudes toward Internet use, work, and possibly discrimination issues.

Economic research on the possible impact of Internet access on work attendance has been sparse. A plausible reason for this may be the lack of data for both Internet use by adults and their work attendance. Given the aforementioned growth rate of Internet use by individuals of all ages, a better understanding about the extent to which Internet access might impact work attendance may prove beneficial toward identification of "at risk" individuals (whose Internet use interferes with day-to-day functioning), for which some type of intervention may be suitable. 
While one may consider this to be an extreme instance, it may well be that those with very high levels of Internet access, and presumably use (e.g. social media, "googleing," pornography), could miss entire days of work to devote to Internet utilization. Discussion of possible intervention techniques is beyond the scope of this paper; however, given the paucity of research in the area of Internet use and its impact on work attendance, results of this study may be considered an important contribution to what is likely to become a growing area of interest by academics and industry practitioners.

\section{Literature Overview}

The literature has been largely silent on the problem of workers' Internet and WWW access and use and its possible impact on absenteeism. Thus, examination of the literature here generally focuses on the impact of attitudes on absenteeism, as well as some of the causes of absenteeism, most of which result from health and gender issues.

A study by Skåtun (2004) investigates the instances where workers who show up for work on any given day have a tendency to perform the work that would otherwise be completed by co-workers who failed to show up for work. Stated differently, when work attendance is generally high, then there is an increased likelihood that workers will show up for work. Results also suggest that management may consider imposing more stringent firing policies for workers who tend to miss work often. Health-related factors may also affect workers' propensity to miss work. The widely held belief (assumption) that smokers miss more work than their nonsmoking counterparts is examined more closely by Ault, Ekelund, Jackson, Saba, and Saurman (1991). Employing a fairly rigorous statistical approach, they find that smokers actually missed no more work days than did non-smokers. Other factors (e.g. age, alcohol consumption) also contribute to perceived absenteeism differences between smokers and non-smokers. In contrast to non-smokers, smokers tend to be younger, heavier drinkers, and employed more as blue-collar workers. Such groups tend to have higher work absences regardless of smoking.

Vistnes (1997) notes that health status, independent of gender, is the primary cause of work absenteeism. Analyzing data compiled from surveys and employers' records, Väänänen, Tordera, Kivimäki, Kouvonen, Pentti, Linna, and Vahtera (2008) examine the effects of group norms and cohesion on sickness absenteeism. They find that a lenient attitude toward work attendance increases the sickness absence rate when employees have minimal group cohesion. However, when either strong group cohesion or a general lack of tolerance toward absences is present, a somewhat decreased absence rate is observed. Thus, the extent to which individuals will demonstrate sickness absences is affected by group absence norms. Unfortunately, none of these studies address the issue of whether (or how) Internet access might impact workers' tendency to miss work.

Gender differences in work absenteeism have been observed. Scott and McClellan (1990), examine absenteeism data for middle school teachers, librarians, and guidance counselors. Results show that women in the study missed a significantly higher number of days than men; however, the number of occurrences of absenteeism was roughly the same between the two groups. Results from (Dellve, Eriksson, and Vilhelmsson, 2007) show a positive relationship between work attendance and variables such as male gender, higher income, work commitment, job satisfaction, and positive work attitudes. Specifically, long-term work attendance as it relates to social, psychosocial, and health issues, are the focus of this study. Their results demonstrate that stable patterns of behavior, more than anything, affected work attendance.

Barmby, Ercolani, and Treble (2002) find that worker characteristics such as age, gender and socio-economic factors that relate to absence due to reported sickness appeared to be consistent across countries, even with wide variations in mean absence rates. Data analysis shows that workers who have more time accumulated with their current organization tend to have higher absence rates, even when controlling for age. Additionally, absence is positively correlated with greater hours of work.

Evans and Steptoe (2002) examine the psychosocial factors related to work stress and gender-role orientation on male- and female-dominated professions. Their research question centers on the premise that health might be impaired among women working in a male-dominated profession (e.g., accounting), with a similar health impairment by men who work in a female-dominated profession (e.g., nursing). Results of their study indicate that there are indeed gender-specific adverse health effects. Data are analyzed from nurses, 172 of which are female and 61 are male, and from commercial accountants, of which 53 are female and 61 are male. 
The results show that female accountants exhibit higher anxiety than their male counterparts, with male nurses having the highest rates of sickness absenteeism in the profession. A longitudinal study by Koopmans, Roelen, Bültmann, Hoedeman, van der Klink, and Groothoff (2010) focuses on the recurrence of sickness absence (by age and gender), due to common mental disorders, such as distress, adjustment and depressive disorders, and anxiety. Their results show that employees who missed work due to common mental disorders are at increased risk of recurrent sickness absence due to such disorders. Recurrence between men and women is similar; however, for women less than 45 years old, recurrence is higher than in women 45 years or older. No age differences among men are indicated. Finally, Ward (2013) examines the effect of video games on work absenteeism. Using reducedform regressions, results suggest that men with lower incomes are more likely to miss work due to playing video games than women. Although this work does not consider the playing of video games as a factor, our emphasis on gender-related Internet access may suggest comparable impacts on work absenteeism.

While gender is an important factor in these studies, none of them seek to explore whether Internet access affects absenteeism from work differently for males and females. In contrast, this article studies this factor while expanding on degree of access/ use.

Moreover, studies in this area have limited sample sizes and work-related variables. In contrast, this analysis employs a larger sample size for which there is greater information on demographics, household characteristics and other factors. Further, the number of variables in the data is large and generally exceeds the number of variables found in the datasets of the above studies.

\section{Data}

The National Survey on Drug Use and Health (NSDUH), sponsored by the Substance Abuse and Mental Health Services Administration (SAMHSA), is administered annually to approximately 55,000 civilian, noninstitutionalized individuals age 12 and over, chosen so that the application of sample weights produces a nationally representative sample with approximately equal numbers of respondents from the $12-17,18-25$, and 26 and over age groups.

Variables on Internet access were collected and compiled by SAMHSA administrators for the 2005 survey only; hence these are the data analyzed. The sample consists of 27,669 currently employed individuals. Of that, 13,712 are male and 13,957 are female. Data from the NSDUH is particularly applicable to coverage of this subject. There is a unique ability to study aspects of labor market outcomes using data from an elaborate questionnaire on a wide array of job experiences. An assortment of variables is observed that have the potential to serve as predictors for absenteeism in the proposed model. Also provided are variables on race, gender, family size, family composition, health, etc.

A potentially problematic attribute of the data is non-random measurement error emanating from the self-reported nature of responses. However, studies on the quality of self-reported variables data suggest that such reporting bias should be minimal. Hunley et al. (2005) address concerns about self-reported survey data by way of demonstration of the reliability of survey data as "appropriate" for accurately measuring Internet use. Specifically, individuals provided estimates of their Internet use, and then logged their actual daily Internet use for a one week period. Comparisons between estimated Internet use and actual use showed reliability of the selfreported estimates. Their conclusion is that researchers should feel confident about self-reported survey data pertaining to Internet use.

\section{Research Method and Empirical Specification}

Consider the following equation (1), in which Absenteeism is a function of exogenous factors with Internet access of prime importance,

(1) Absenteeism $=\beta_{0}+\beta_{1} \mathrm{IA}+\beta_{2} \mathrm{X}+\varepsilon$.

In the above equation, which applies to individual NSDUH respondents (with the corresponding observation-level subscript suppressed), IA represents venues of Internet access and usage in the past 30 days. Vector X represents a set of other exogenous variables that conceivably affect absenteeism.

Given that absenteeism is generally limited to relatively small number of days (approximately 97 percent of respondents report missing four days of work or less), a poisson regression is utilized. The analysis is conducted utilizing a sample of currently working individuals (ages 17-65+ years old). 


\subsection{Absenteeism}

All respondents are asked to report the number of work days (ranging from 0 to 30) over the past 30 days that were missed because of illness or injury, as well as days missed due to "skipping" work. The former merits attention in that Internet utilization may be the reason for reporting illness or injury. In other words, people may fake illness in order to spend time on the Internet.

\subsection{Internet Access and Usage}

When the survey is administered, respondents are queried on venues of Internet utilization in the past 30 days. Individuals actually used the Internet via these venues. In the study, Internet users are categorized in two forms: Level 1 and Level 2. Another category incorporates those that had no Internet access in the past 30 days - as described below, that category is omitted in the regressions.

For those in Level 1, the Internet could be utilized at home, at a friend's house, at a café with Internet access, over a cell phone and some other place - this variable is "open" and does not have specific options. For those in Level 2 , the Internet was utilized only at a library.

Those in Level 1 are defined as having intense Internet access; those in Level 2 as having light access. For light access, Internet access is subject to time constraints (i.e. hours of operation for libraries), whereas for intense access, there is virtual 24 hour access. In regressions, those that did not access the Internet (no use) in the past 30 days is the omitted category and is used as the category of comparison.

\subsection{Other Explanatory Variables}

Several variables from the NSDUH data are considered explanatory in equation (1): an age indicator is included for whether the individual is under 21 years old. An indicator for risk associated with alcohol consumption is included and could be considered a proxy for overall risk aversion. This is measured on a 1-4 scale, with ' 1 ' indicating no risk and '4' indicating very risky. Those with higher levels of risk aversion may invest more in human capital and therefore have lower rates of absenteeism. Furthermore, the number of times someone moved in the last year is incorporated as this could proxy for "job hopping" which in turn can affect absenteeism. Family size is measured by two variables: number in the family from one to five members and a binary indicator for a family of over six members. The latter measure in particular may indicate a high opportunity cost of working, which, in turn can affect work absences. A binary variable is also included to denote those that live in a large MSA (over 1 million) and those in smaller MSA's (under 1 million). Those in larger MSAs could enjoy more Internet accessibility through more updated networks, better library resources, etc. And those in larger MSAs may also enjoy greater job/ career opportunities.

To control for the possibility that certain jobs with differing responsibilities are represented predominately by a certain racial group, indicators are specified for Caucasians, African Americans and Asians and non-white Hispanics with multiracial as the omitted category. Further, physical health is measured as follows: great health, good health and fair health with poor health as the omitted category. Those in poorer health will naturally have more work absenteeism. Of prime importance are gender differences. In the following section, the results are presented by dividing the sample by males and females.

\section{Empirical Findings}

Table 1 presents select summary statistics for the male/ female subsets of data. The mean number of days missed due to skipping is 0.66 for males and 0.83 for females while mean sick days is about one-third of a day for males and 0.231 for females. Intense Internet access is 0.046 (males) and 0.047 (females) and light access is lower with a mean of 0.166 (males) and 0.178 (females). About 0.20 of both genders reported no Internet access in the past 30 days. 
Table 1. Descriptive Statistics

male sample $(n=13,712) \quad$ female sample $(13,957)$

\begin{tabular}{|c|c|c|c|c|}
\hline Variable & Mean & $\begin{array}{l}\text { Standard } \\
\text { De viation }\end{array}$ & Mean & $\begin{array}{l}\text { Standard } \\
\text { Deviation }\end{array}$ \\
\hline \# of days missed due to skipping (past 30 days) & 0.659 & 2.535 & 0.826 & 2.876 \\
\hline \# of days missed due to reported illness (past 30 days) & 0.299 & 1.335 & 0.231 & 1.124 \\
\hline Intense Internet Access (past 30 days) & 0.046 & 0.209 & 0.047 & 0.210 \\
\hline Light Internet Access (past 30 days) & 0.166 & 0.373 & 0.178 & 0.383 \\
\hline No Internet Access (past 30 days) & 0.226 & 0.321 & 0.194 & 0.283 \\
\hline Respondent under 21 years old & 0.236 & 0.425 & 0.227 & 0.418 \\
\hline Risk of bodily harm from consuming 4-5 drinks per day ( $1-5$ scale) & 0.871 & 0.336 & 0.937 & 0.243 \\
\hline Race (Caucasian) & 0.646 & 0.478 & 0.635 & 0.481 \\
\hline Race (African American) & 0.115 & 0.319 & 0.132 & 0.338 \\
\hline Race (Asian) & 0.035 & 0.183 & 0.032 & 0.175 \\
\hline Race (non-white Hispanic) & 0.158 & 0.365 & 0.155 & 0.362 \\
\hline Race (multiracial) & 0.030 & 0.378 & 0.299 & 0.362 \\
\hline Family income $(<75,000)$ & 0.238 & 0.438 & 0.216 & 0.419 \\
\hline number of times moved (past year) & 0.481 & 0.832 & 0.509 & 0.850 \\
\hline number in family & 3.052 & 1.423 & 3.030 & 1.433 \\
\hline number in family $>6$ & 0.103 & 0.304 & 0.104 & 0.306 \\
\hline MSA segement with $1+$ million persons & 0.418 & 0.493 & 0.422 & 0.494 \\
\hline MSA segment of less than 1 million & 0.490 & 0.500 & 0.486 & 0.500 \\
\hline Health status (great) & 0.296 & 0.457 & 0.285 & 0.451 \\
\hline Health status (good) & 0.399 & 0.490 & 0.404 & 0.491 \\
\hline Health status (fair) & 0.244 & 0.430 & 0.247 & 0.431 \\
\hline
\end{tabular}

Both genders perceive that a moderately large risk in consuming 4-5 drinks per day. Caucasians comprise approximately 65 percent for both the male and female samples, African Americans about 12 percent, and nonwhite Hispanics and Asians account for about 15 percent and three percent, respectively. Average family size is about three members and approximately ten percent report family size of six or more. About 20 percent of both genders report family income above $\$ 75,000$ and roughly equal proportions of both genders report great, good or fair health.

\subsection{The Effects of Internet Access on Days of Work Missed Due to Skipping}

As shown in Table 2, intense Internet access is significant and increases days missed of work due to skipping by 0.204 days for females, compared to no Internet access. For males, there is no significant effect. Interestingly, light Internet access lowers days skipped by 0.190 days for females while not affecting any tendency by males to skip work. 
Table 2. Poisson regression estimates for days missed (skipping)

\begin{tabular}{|c|c|c|c|c|}
\hline Explanatory variables & Coefficient & Standard Error & Coefficient & Standard Error \\
\hline Intense Internet Access (past 30 days) & -0.012 & $(0.051)$ & $0.204 *$ & $(0.042)$ \\
\hline Light Internet Access (past 30 days) & 0.021 & $(0.031)$ & $-0.190 *$ & $(0.027)$ \\
\hline Respondent is under 21 years old & $0.137 *$ & $(0.024)$ & $-0.055 * *$ & $(0.022)$ \\
\hline Risk of bodily harm from consuming $4-5$ drinks per day ( $1-5$ scale) & $0.118^{*}$ & $(0.032)$ & $-0.160 *$ & $(0.040)$ \\
\hline Race (Caucasian) & $-0.372 *$ & $(0.045)$ & $-0.188^{*}$ & $(0.045)$ \\
\hline Race (African American) & $-0.373 *$ & $(0.056)$ & $0.271 *$ & $(0.049)$ \\
\hline Race (Asian) & $-0.361 *$ & $(0.072)$ & $-0.352 *$ & $(0.075)$ \\
\hline Race (non-white Hispanic) & $-0.510 *$ & $(0.051)$ & $-0.120 *$ & $(0.050)$ \\
\hline Family income $(<75,000)$ & $-0.274 *$ & $(0.027)$ & $-0.159 *$ & $(0.026)$ \\
\hline number of times moved (past year) & $0.103^{*}$ & $(0.011)$ & $0.144 *$ & $(0.010)$ \\
\hline MSA segement with $1+$ million persons & $0.092 * *$ & $(0.042)$ & $0.126^{*}$ & $(0.037)$ \\
\hline MSA segment of less than 1 million & $0.177 *$ & $(0.040)$ & $0.090^{*}$ & $(0.036)$ \\
\hline number in family & 0.016 & $(0.011)$ & $0.039 *$ & $(0.009)$ \\
\hline number in family $>6$ & $0.135^{*}$ & $(0.052)$ & $0.248^{*}$ & $(0.046)$ \\
\hline Health status (great) & $-1.141 *$ & $(0.039)$ & $-0.931 *$ & $(0.035)$ \\
\hline Health status (good) & $-0.853 *$ & $(0.035)$ & $-0.823^{*}$ & $(0.032)$ \\
\hline Health status (fair) & $-0.621 *$ & $(0.036)$ & $-0.575^{*}$ & $(0.033)$ \\
\hline
\end{tabular}

*statistically significant at $1 \%$

**statistically significant at $5 \%$

****statistically significant at $10 \%$

There is a gender disparity in days missed because of skipping for intense Internet access. Female intense access leads to more skipping versus those who have no access; there is no effect for males. It may be hypothesized that females access the Internet for the social "give and take" of Internet discourse that occurs instantaneously, versus more leisure male use such as gaming, music sharing, etc. Hence, utility maximizing male Internet access may be attained more sporadically while utility maximizing female use is more time intensive and may necessitate more female work absenteeism.

\subsection{The Effects of Internet Access on Days of Work Missed Due to Sickness}

As shown in Table 3, intense Internet access increases days missed due to sickness by 0.122 days for males and 0.143 days (slightly more) for females, versus no Internet access. Also, light Internet access has no significant effect. 
Table 3. Poisson regression estimates for days missed (sickness)

male sample $(\mathrm{n}=13,712) \quad$ female sample $(13,957)$

\begin{tabular}{lcccc} 
Intense Internet Access (past 30 days) & $0.122^{* *}$ & $(0.071)$ & $0.143^{* * *}$ & $(0.080)$ \\
Light Internet Access (past 30 days) & 0.016 & $(0.045)$ & -0.072 & $(0.048)$ \\
Respondent is under 21 years old & $0.321^{*}$ & $(0.034)$ & $0.250^{*}$ & $(0.038)$ \\
Risk of bodily harm from consuming 4-5 drinks per day $(1-5$ scale) & $-0.207^{*}$ & $(0.043)$ & $-0.327^{*}$ & $(0.070)$ \\
Race (Caucasian) & $-0.780^{*}$ & $(0.060)$ & $-0.600^{*}$ & $(0.074)$ \\
Race (African American) & $-0.262^{*}$ & $(0.071)$ & -0.104 & $(0.083)$ \\
Race (Asian) & $-0.587^{*}$ & $(0.099)$ & $-0.313^{*}$ & $(0.118)$ \\
Race (non-white Hispanic) & $-0.751^{*}$ & $(0.070)$ & $-0.238^{*}$ & $(0.082)$ \\
Family income (<75,000) & $-0.091^{* * *}$ & $(0.039)$ & $-0.254^{*}$ & $(0.048)$ \\
number of times moved (past year) & $0.121^{*}$ & $(0.017)$ & $0.146^{*}$ & $(0.019)$ \\
MSA segement with 1+ million persons & $0.102^{* * *}$ & $(0.062)$ & 0.124 & $(0.066)$ \\
MSA segment of less than 1 million & 0.064 & $(0.060)$ & $-0.207^{*}$ & $(0.066)$ \\
number in family & 0.011 & $(0.016)$ & $0.083^{*}$ & $(0.017)$ \\
number in family>6 & $0.268^{*}$ & $(0.075)$ & 0.127 & $(0.091)$ \\
Health status (great) & $-0.380^{*}$ & $(0.069)$ & $-0.285^{*}$ & $(0.076)$ \\
Health status (good) & -0.121 & $(0.065)$ & $-0.167^{* *}$ & $(0.072)$ \\
Health status (fair) & -0.050 & $(0.067)$ & -0.102 & $(0.074)$ \\
\hline
\end{tabular}

*statistically significant at $1 \%$

$* *$ statistically significant at $5 \%$

$* * *$ statistically significant at $10 \%$

Since intense access is significant and positive for both genders, and since other variables are controlled including current health status, it can be hypothesized that these individuals may feign illness in order to spend more time on the Internet. Moreover, gender differences are apparent for this absenteeism variable.

\subsection{The Effects of Internet Access on the Probability of Missing Five-plus Days Due to Skipping/ Sickness}

In Table 4, probit results show the effect of Internet access on the probability someone skips five or more days of work is generally insignificant for both males and females. However, it is worth noting that females who have light Internet access have a decreased probability of skipping five-plus days by roughly 0.01.For these female respondents the probability of skipping five-plus days is reduced by about 1.5 percent, compared to those who had no Internet access at all in the past 30 days. 


\begin{tabular}{|c|c|c|c|c|c|c|c|c|}
\hline \multirow[b]{4}{*}{ Explanatory variables } & \multicolumn{4}{|c|}{ Skipping } & \multicolumn{4}{|c|}{ Sickness } \\
\hline & \multicolumn{2}{|c|}{ male sample $(\mathrm{n}=13,712)$} & \multicolumn{2}{|c|}{ female sample $(13,957)$} & \multicolumn{2}{|c|}{ male sample $(\mathrm{n}=13,712)$} & \multicolumn{2}{|c|}{ female sample $(13,957)$} \\
\hline & & Robust & & Robust & & Robust & & Robust \\
\hline & Coefficient & Standard Error & Coefficient & Standard Error & r Coefficient & Standard Error & Coefficient & Standard Error \\
\hline Intense Internet Access (past 30 days) & -0.006 & $(0.007)$ & 0.003 & $(0.009)$ & 0.007 & $(0.006)$ & $0.008^{*}$ & $(0.006)$ \\
\hline Light Internet Access (past 30 days) & 0.003 & $(0.005)$ & $-0.009 * * *$ & $(0.003)$ & 0.002 & $(0.003)$ & -0.002 & $(0.002)$ \\
\hline Respondent is under 21 years old & 0.004 & $(0.004)$ & -0.003 & $(0.004)$ & $0.010^{*}$ & $(0.003)$ & $0.003 * *$ & $(0.002)$ \\
\hline Risk of bodily harm from consuming $4-5$ drinks per day ( $1-5$ scale) & 0.002 & $(0.005)$ & -0.009 & $(0.008)$ & -0.005 & $(0.004)$ & -0.007 & $(0.005)$ \\
\hline Race (Caucasian) & $-0.014 * *$ & $(0.008)$ & $-0.017 * * *$ & $(0.009)$ & $-0.017^{*}$ & $(0.006)$ & $-0.013 *$ & $(0.005)$ \\
\hline Race (African American) & $-0.012 * * *$ & $(0.007)$ & 0.014 & $(0.010)$ & $-0.010 * *$ & $(0.003)$ & -0.002 & $(0.004)$ \\
\hline Race (Asian) & -0.007 & $(0.010)$ & $-0.021 * *$ & $(0.008)$ & $-0.012 * *$ & $(0.004)$ & -0.002 & $(0.005)$ \\
\hline Race (non-white Hispanic) & $-0.014 * *$ & $(0.006)$ & -0.007 & $(0.008)$ & $-0.013^{*}$ & $(0.003)$ & -0.004 & $(0.003)$ \\
\hline Family income $(<75,000)$ & $-0.011^{* *}$ & $(0.003)$ & -0.004 & $(0.004)$ & -0.001 & $(0.003)$ & -0.001 & $(0.002)$ \\
\hline number of times moved (past year) & $0.005^{*}$ & $(0.002)$ & $0.008^{*}$ & $(0.002)$ & $0.002 * *$ & $(0.001)$ & $0.002 *$ & $(0.001)$ \\
\hline MSA segment with $1+$ million persons & -0.002 & $(0.006)$ & 0.005 & $(0.007)$ & 0.002 & $(0.004)$ & -0.002 & $(0.003)$ \\
\hline MSA segment of less than 1 million & 0.004 & $(0.006)$ & 0.005 & $(0.007)$ & 0.001 & $(0.004)$ & $-0.007^{* *}$ & $(0.003)$ \\
\hline number in family & 0.001 & $(0.016)$ & $0.001^{*}$ & $(0.017)$ & 0.001 & $(0.001)$ & 0.001 & $(0.001)$ \\
\hline number in family $>6$ & 0.009 & $(0.008)$ & 0.009 & $(0.091)$ & $0.012 * *$ & $(0.008)$ & 0.001 & $(0.004)$ \\
\hline Health status (great) & $-0.078 *$ & $(0.005)$ & $-0.045^{*}$ & $(0.005)$ & $-0.001 * *$ & $(0.004)$ & -0.002 & $(0.004)$ \\
\hline Health status (good) & $-0.031 *$ & $(0.006)$ & $-0.048^{*}$ & $(0.006)$ & 0.000 & $(0.005)$ & -0.002 & $(0.004)$ \\
\hline Health status (fair) & $-0.019 *$ & $(0.005)$ & $-0.030 *$ & $(0.005)$ & 0.000 & $(0.005)$ & -0.002 & $(0.004)$ \\
\hline
\end{tabular}

In most instances, the effect of Internet access on the probability an individual reports illness five or more days is insignificant for both males and females. Nonetheless, females who have intense access have an increased probability of reporting sickness for five-plus days by 0.008 - for these females the probability of reporting this measure of sickness is raised by about 3.4 percent compared to females who did not use the Internet at all in the past 30 days.

\subsection{The Effects of Other Explanatory Variables on Absenteeism}

Many of the other explanatory variables have a significant impact on work absences. Younger males (under 21) missed more days because of skipping than those over 21. Females under 21 actually missed fewer days due to skipping though the effect is very small. More risk averse males (as measured by risk associated with drinking) are less likely to miss work due to sickness as are females. Interestingly, males with higher risk aversion with respect to alcohol are more likely to miss work due to skipping while females are less likely .Of course for males, this may reflect an increased opportunity cost involved in work attendance and a possibly a more lax work ethic. For older females, time involved with children and other family issues may be a partial explanation for their increased work skipping vis-à-vis younger females.

In addition, for both genders, Caucasians and African Americans, Asians and non-white Hispanics have fewer days missed due to skipping and illness compared to multiracial. For both the male and female sample, increases in the incidence of moving increases both measures of absenteeism. Growth in family size and especially large family sizes (over six members) generally increase both work absenteeism measures on the part of both genders. Rises in skipping may be attributable to rising opportunity cost of working and, for missing work due to illness, the greater spreading of sickness as family size grows. Those with high incomes (over $\$ 75,000$ ) miss fewer days of work (both skipping and sickness) than those with more moderate and lower incomes and this holds for both genders. Of course, this may be explained by the fact that higher paying jobs require more responsibility and therefore absenteeism is naturally less. In addition, as one might intuitively expect, male and female respondents that are in better health report fewer days missed due to skipping and illness.

\subsection{General Comparisons}

While we control for a host of demographic and economic factors, the results demonstrate that Internet access largely does not influence work absenteeism in the form of "skipping" for males but it does for females. Intense Internet access does appear to influence work absenteeism from reported sickness for both genders. 
Excessive work absenteeism (five-plus days) is not affected by intense Internet access on the part of males. For females, Internet access does have some significant influences on excessive work absences. Generally the totality of the results shows that females with "greater consumption" of the Internet have higher rates of absenteeism versus "less consumption" of the Internet - for males, Internet access has fewer significant effects.

\section{Concluding Remarks}

Some evidence is presented that work absenteeism is elevated when additional venues of Internet access are utilized and gender issues are noteworthy. Indeed individuals, both male and female, may be missing work, to some extent, to "surf the "net" but the genders are unequally affected. Female work absenteeism is somewhat elevated vis-à-vis male absenteeism and Internet factors appear to play a role. While empirical evidence is not offered, it is hypothesized that female Internet use, most likely via social networking, is more time intensive thus engendering more absenteeism. Also, this study adds to a general line of research that has revealed gender differences in labor market outcomes.

The results provide useful information to employers, employment counselors, and even workers as they consider implications for the appropriateness of Internet use. There is an important qualification: the data did not explicitly outline whether individuals' Internet use was for work-related or social purposes. Therefore, future research that incorporates this data would provide more information.

\section{References}

Ault, R. W., Ekelund, Jr., R. B., Jackson, J. D., Saba, R. S., and Saurman, D. S. (1991). Smoking and absenteeism. Applied Economics,23, 743-754.

Barmby, T., Ercolani, M. and Treble, J. (June 2002). Sickness absence: an international comparison. The Economic Journal, 112, F315-F331.

Dellve, L., Eriksson, J., and Vilhelmsson, R. (2007). Assessment of long-term work attendance within human service organizations. Work, 29, 71-80.

Evan, O. and Steptoe, A. (2002). The contribution of gender-role orientation, work factors and home stressors to psychological well-being and sickness absence in male- and female-dominated occupational groups. Social Science \& Medicine, 4, 481-492.

Hunley, S. A., Evans, J. H., Delgado-Hachey, M., Krise, J., Rich, T. and Schell, C. (2005).Adolescent computer use and academic achievement. Adolescence, 40, 307-318.

Koopmans, P. C., Roelen, C. A., Bültmann, U., Hoedeman, R., van der Klink, J. J. and Groothoff, J. W. (2010). Gender and age differences in the recurrence of sickness absence due to common mental disorders: a longitudinal study.BMC Public Health, 10 (426). [Online] Available: http://www.biomedcentral.com/1471-2458/10/426 (Accessed 21 October 2010)

Pew Internet \& American Life Project Surveys (2015). [Online]. Available: http://www.pewinternet.org/TrendData/Internet-Adoption.aspx (Accessed 4 August 2015)

Scott, K. D. and McClellan, E. L., (1990).Gender differences in absenteeism, Public Personnel Management. 2, 229-253.

Väänänen, A., Tordera, N., Kivimäki, M., Kouvonen, A., Pentti, J., Linna, A., and Vahtera, J. (2008).The role of work group in individual sickness absence behavior. Journal of Health and Social Behavior, 9, 452-467.

Vistnes, Jessica P (1997). Gender differences in days lost from work due to illness. Industrial and Labor Relations Review, 50, 2, 304-323.

Ward, Michael R. (2013). Video Games and Absenteeism. [Online] Available SSRN: http://ssrn.com/abstract=2061726 or http://dx.doi.org/10.2139/ssrn.2061726. (October 2013) 